
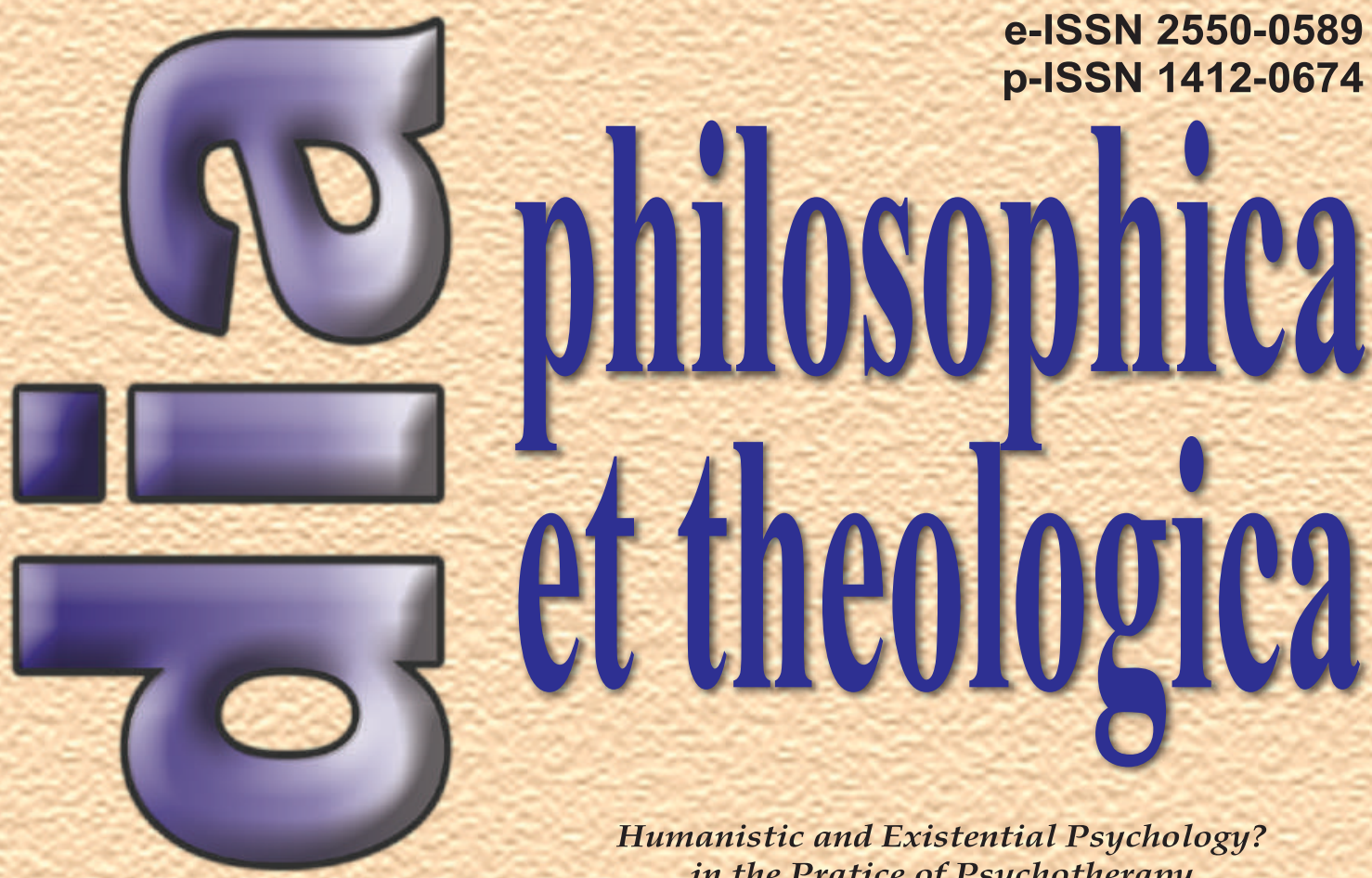

Humanistic and Existential Psychology? in the Pratice of Psychotherapy Aureliano Pacciolla

Visi Eskatologi - Kreatif da Eksemplaris - Terbuka Christanto Sema Raffan Paledung

Tentang Harmoni Antara Tuhan, Manusia dan Alam Dalam Tradisi Beduruk Di Dusun Medang Fransiskus Gregorius Nyaming
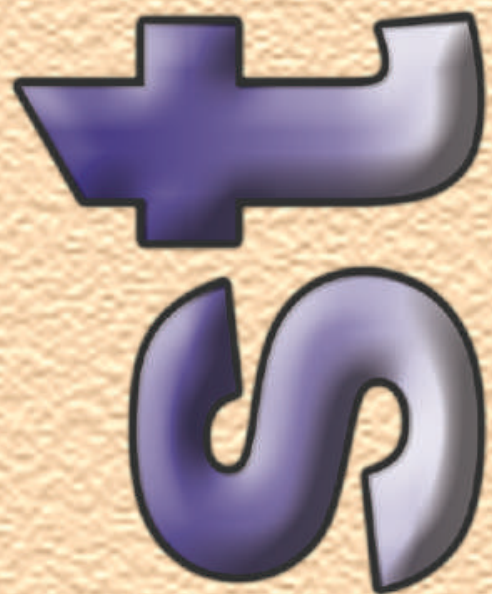

Tergeraklah Hatinya oleh Belas Kasihan Belajar dari Perumpamaan Orang Samaria yang Murah Hati (Luk. 10:25-37) Benny Phang

Hutan Dibabat, Masyarakat Melarat, Masa Depan Gelap I Ketut Gegel

Awal Moral Kristiani Edison R.L. Tinambunan $* * * * *$

TELAAH BUKU

Sekolah Tinggi Filsafat Teologi

Vol. 19 No. 1 April 2019 Widya Sasana, Malang 


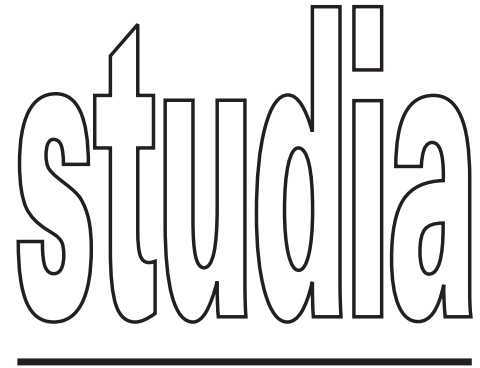

STUDIA PHILOSOPHICA ET THEOLOGICA (ISSN Print 1412-0674 and ISSN Online 2550-0589) is a bilingual (Indonesian and English language) and peer reviewed journal published by Center of Research of Widya Sasana School of Philosophy Theology, Malang. STUDIA specializes in researched papers related to contextualization and inculturation of theology and philosophy from inter-disciplinary-methodological point of view. Journal has 2 issues per year (April and October).

STUDIA welcomes philosophical and theological contributions from scholars with various background of disciplines. This journal uses English and Indonesian Language. STUDIA is an open access journal whose papers published is freely downloaded.

\section{FOCUS AND SCOPE:}

STUDIA focuses on philosophical and theological studies based on both literary and field researches. The emphasis of study is on systematic attempt of exploring seeds of Indonesian philosophy as well as contextualization and inculturationof theology in socio-political-historical atmosphere of Indonesia.

Scope of STUDIA covers various perspectives of philosophical and theological studies from interdisciplinary methodology and cultural-religious point of view of traditions.

\section{PUBLISHER :}

P3M Sekolah Tinggi Filsafat Teologi

Widya Sasana Malang

Jl. Terusan Rajabasa 2,

Malang 65146 Indonesia

Telp. $0341-552120$

Fax. $0341-566676$

Email : stftws@gmail.com

Website : ejournal.stftws.ac.id
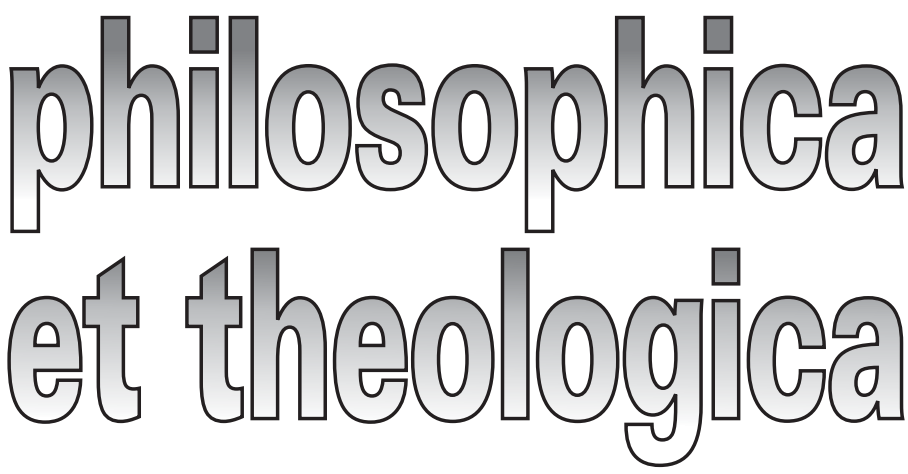

e-ISSN 2550-0589
p-ISSN 1412-0674

Editor

Edison RL. Tinambunan (Google Scholar; h-index: 1); Widya

Sasana College of Philosophy Theology, Malang. (Editor-in-Chief)

\section{Editorial Board}

FX. Eko Armada Riyanto (Google Scholar; h-index: 5); Widya Sasana College of Philosophy Theology, Malang.

Kurniawan Dwi Madyo Utomo (Google Scholar); Widya Sasana College of Philosophy Theology, Malang.

Pius Pandor (Google Scholar; h-index: 2); Widya Sasana College of Philosophy Theology, Malang.

Valentinus Saeng (Google Scholar; h-index: 2); Widya Sasana College of Philosophy Theology, Malang.

Yohanes I Wayan Marianta (Google Scholar); Widya Sasana College of Philosophy Theology, Malang.

Raymundus Made Sudhiarsa (Google Scholar; h-index: 2); Widya Sasana College of Philosophy Theology, Malang.

Alphonsus Catur Raharso (Google Scholar; h-index: 2); Widya Sasana College of Philosophy Theology, Malang.

Petrus Maria Handoko (Google Scholar; h-index: 2); Widya Sasana College of Philosophy Theology, Malang.

Antonius Denny Firmanto (Google Scholar; h-index: 2); Widya Sasana College of Philosophy Theology, Malang.

Carl Sterkens (Scopus ID: ... ; Google Scholar; h-index: 7); Katholic Radboud University, Nijmegen, Niederlands.

Daniel Franklin Pilario(Google Scholar; h-index: 4); Adamson University, Manila, Philippines.

Roland Tuazon (Google Scholar; h-index: 2); Adamson University, Manila, Philippines.

Emanuel P.D. Martasudjita (Scopus ID: 6026801; Google Scholar; h-index: 4); Sanata Dharma University, Yogyakarta.

Johanis Ohoitimur (Google Scholar; h-index: 3); Pineleng College, Manado.

Antonius Eddy Kristiyanto (Google Scholar; h-index: 5); Driyarkara College, Jakarta.

Mudjia Rahardja (Scopus ID: ... Google Scholar; h-index: 10); Maulana Malik Ibrahim Islamic State University, Malang.

Justinus Sudarminta (Google Scholar; h-index: 7); Driyarkara College, Jakarta.

\section{English Language Advisor}

Maria Lichmann (North Carolina)

Odilia Rahayu Widji Astuti

\section{Indonesian Language Advisor}

Didik Bagiyowinadi

\section{Information and Technology}

Imilda Retno Arum Sari

\section{Publication Frequency}

Studia Philosophicaet Theologica is published two times a year (April and October) 


\section{Author Guidelines}

1. Article must have150-word abstract in both English and Indonesian language and four or five keywords.

2. Article should be between 5000 and 8000 words, inclusive of references and footnotes.

3. Article must be a study based on either literary (text) or field research.

4. Article will be submitted in Word (single-spaced and 12-point font) for consideration by email attachment, beside online submission as required. Authors must log in before submit their article.

5. Headings:

- First-level headings (e.g. Introduction, Conclusion) should be in bold, with an initial capital letter for any proper nouns.

- Second-level headings should be in bold italics, with an initial capital letter for any proper nouns.

- Third-level headings should be in italics, with an initial capital letter for any proper nouns.

6. Notes and Bibliographies please click https://www.dropbox.com/s/y2nb9l3cvb9 fg47/Notes\%20and\%20Bibliography\%20Turabian\%20Style.pdf? $d l=0$.

7. Article submitted will be peer-reviewed by qualified academics; this process may take weeks or months. All submitted papers are subject to review of the editors, editorial board, and reviewers.

8. Author should be willing to respond to questions from readers of their articles; and in case there is correction, author must refine the article as soon as possible.

\section{Guidelines for Book Reviews}

1. Please include, at the beginning: Author, Title, Place, Publisher, Date, number of pages, ISBN of the book reviewed.

E.g., Taylor, Charles. A Secular Age. Cambridge: The Belknap Press of Harvard University Press, 2007. 874+x pp. ISBN-13: 978-0-674-02676-6.

2. The review begin with abstract, three or four keywords and continue with a brief overall description of the book.

3. The review may include:

- The content and its complexity of the book.

- Comments on the author's style and contribution of the book.

- Philosophical or theological methodology of presentation.

- Position of the philosophical or theological arguments in its field.

4. The preferred format for submissions is MS-Word.

5. Review should be about 1500 words long. The name, affiliation and email address of the reviewer should appear at the end of the review. 


\section{Studia Philosophica et Theologica E-ISSN 2550 - 0589 \\ ISSN 1412-0674 \\ Vol. 19 No. 1 April 2019 \\ Hal. 1 - 118}

\section{DAFTAR ISI}

\section{ARTIKEL}

Humanistic and Existential Psychology

in the Pratice of Psychotherapy

Aureliano Pacciolla

Visi Eskatologis - Kreatif dan Eksemplaris - Terbuka

Sebagai Model Kehadiran Kristen dalam Konteks Indonesia

Christanto Sema Raffan Paledung

Tentang Harmoni Antara Tuhan, Manusia dan Alam

Dalam Tradisi Beduruk Di Dusun Medang

Fransiskus Gregorius Nyaming

Tergeraklah Hatinya oleh Belas Kasihan: Belajar dari

Perumpamaan Orang Samaria yang Murah Hati (Luk. 10:25-37)

Dalam Mengasihi Embrio Manusia Sebagai Sesama

Benny Phang

$57-79$

Hutan Dibabat, Masyarakat Melarat, Masa Depan Gelap

Refleksi Teologis atas Keberpihakan Gereja Terhadap Masyarakat

Dalam Upaya Pelestarian Alam

I Ketut Gegel

Awal Moral Kristiani

Edison R.L. Tinambunan.

$98-114$ 


\section{TELAAH BUKU}

Relasionalitas Filsafat Fondasi Interpretasi:

Aku, Teks, Liyan, Fenomena

Donatus Sermada Kelen ........................................................ 115 - 118 


\title{
AWAL MORAL KRISTIANI
}

\author{
Edison R.L. Tinambunan ${ }^{1}$
}

\begin{abstract}
The development of Christian moralitytakes a long journeywhich was started when the Church was born. There were many typical moral cases faced by the Church at each period of time. From one period to another one, moralists came out to solve the cases by giving the right assessment according to the Church's way of life. A period which was well-knownin the journey of Christian morality is the period of the Fathers of the Church. The principle of Christian morality is love which is based on the Gospel and the commandment of Jesus Christ. This was documented inDidachewhich was used by the Christians at that time. It was the principal moral document of early Christianity. In the development, it was then added by other principals: freedom and justice which were applied in the Christian life. The three principals (love, freedom and justice) formed Christian attitude in respectingother Christians and all people which is applied perfectly by Augustine. The following development of Christian morality was the development of the practice and the profound of what had been laid down before by the Fathers of the Church, with addition of the figure which is excelling in the life as Job, who had been interpreted by Gregory the Great. This writing is ended at this point, because the research is limited from the beginning up to the first development of Christian morality during the period of the Fathers of the Church.
\end{abstract}

Key words: morality; love; freedom; justice

\begin{abstract}
Abstrak
Moral Kristiani saat ini memiliki perkembangan yang sangat luar biasa dalam arti subyek dan pendekatan seiring perkembangan zaman yang ditandai dengan berbagai persoalan hidup yang selalu bermunculan. Perkembangan teknologi dan sosial menjadi pemicunya. Untuk menghadapi fenomena yang setiap saat muncul, Gereja bergerak untuk memberikan penilaian agar Kristiani tahu untuk bersikap dan menghadapinya. Realitas ini tidak akan pernah bisa diabaikan begitu saja, tetapi harus dihadapi dengan sikap yang benar.
\end{abstract}

Perjalanan moral Kristiani telah berlangsung begitu panjang, bisa dikatakan sejak kristianitas lahir. Ada begitu banyak permasalahan moral dihadapi oleh

1 Penulis adalah dosen STFT Widya Sasana, Malang. 
Gereja dalam kurun waktu tersebut. Para moralis pun bermunculan dari periode satu dengan berikutnya untuk memberikan penilaian yang benar dari pihak Gereja untuk cara hidup yang sesungguhnya. Salah satu periode yang perlu diketahui dalam perjalanan moral adalah Bapa Gereja yang bisa disebut sebagai awal moral kristianitas. Tulisan ini akan memberikan aspek-aspek moral yang diajarkan oleh Bapa Gereja yang berkaitan dengan situasi hidup Gereja pada periode tersebut.

Kata Kunci: moral; kasih; kebebasan; keadilan

Moral Kristiani purba yang diungkapkan di dalam sikap, didasarkan pada Kitab Suci, terlebih-lebih Perjanjian Baru. Pendasaran utama yang digunakan adalah kasih terhadap Tuhan dan Sesama, ${ }^{2}$ yang dihubungkan dengan hukum Perjanjian Lama. Artinya adalah bahwa seluk beluk moral berkaitan dengan hukum atau perintah, bahkan suatu peraturan yang berusaha mengarahkan hidup Kristiani pada cara hidup yang sesungguhnya. Oleh sebab itu, pada Kristiani awali, prinsip moral dihubungkan dalam bentuk peraturan. Jika konteks Injil yang direferensikan diperhatikan, maka latarbelakangnya adalah sama, karena seorang Farisi datang kepada Yesus dan menanyakan hukum yang paling utama. Jawaban Yesus adalah kasih. ${ }^{3}$

\section{Kasih}

Bentuk ajaran moral pertama Kristiani terdapat dalam Didache, ${ }^{4}$ yang diatur pada enam nomor pertama. Sesudah itu diikuti dengan liturgi dan disiplin dan ditutup dengan eskatologi. Peraturan moral ini dibuka dengan dua arahan jalan; satu jalan menuju kehidupan dan satunya menuju kematian. ${ }^{5}$ Cara untuk menuju kehidupan dinyatakan dari nomor 1-4; sementara itu nomor 5 adalah sikap untuk jalan menuju kematian dan ditutup dengan nomor 6 yang menyatakan perintah untuk melaksanakan jalan untuk menuju kehidupan adalah suatu kesempurnaan

2 Mrk. 12:30-32 dan pararelnya.

3 Mrk. 12:28 dan pararelnya.

4 Sampai sekarang para ahli masih memiliki pemikiran berbeda mengenai waktu penulisan Didache. Waktu penulisan itu adalah sekitar tahun 50 atau sekitar tahun 70 atau sekitar tahun 100. Antonio Quacquarelli (ed.), "Introduzione", I Padri Apostolici (Roma: Città Nuova Editrice, 1994), 26. Sumber untuk Didache diambil dari edisi buku ini.

5 Bdk. Yer. 21:8; Deut. 30:15-19; Mat. 7:13-14. 
hidup. Jalan kehidupan itu adalah mencintai Tuhan yang telah menciptakan manusia dan mencintai sesama seperti diri sendiri. ${ }^{6}$ Jangan berbuat sesuatu yang jahat pada sesamamu, supaya kamu juga tidak diperbuat setimpal. ${ }^{7}$ Ajaran yang ditampilkan dari jalan menuju kehidupan adalah,

Berkatilah mereka yang berbuat jahat, berdoalah kepada musuh, berpuasalah bagi penganiaya! Apa jasamu, jika kalian mencintai mereka yang mencintai? Orang pagan juga berbuat hal yang sama. Oleh sebab itu, cintailah mereka yang membenci, ${ }^{8}$ agar tidak memiliki musuh! Jauhkanlah kenikmatan daging dan kelobaan materi! Berikanlah pipi kirimu, kalau pipi kananmu ditampar! 9 Dengan cara itu kamu menjadi sempurna. Berjalanlah dua mil, kalau diminta satu mil! Jika orang menanggalkan jeketmu, maka berikanlah juga jubahmu!10 Jika ada orang mengambil barangmu, maka janganlah meminta kembali! Janganlah kamu lakukan ini! Jika ada orang meminta, berilah dan janganlah meminta kembali!11 Bapa menghendaki agar orang memberikan miliknya. Berbahagialah mereka yang memberikan menurut perintah (kasih), karena ia tidak akan dihukum. Sementara itu celakalah orang yang menerima; jika orang menerima sesuatu yang dibutuhkannya, maka ia tidak bersalah; tetapi jika orang menerima sesuatu yang tidak dibutuhkannya, maka akan diperhitungkan kepadanya karena menerima dan tidak membutuhkannya. Ia akan diadili atas perbuatannya dan akan dimasukkan ke penjara dan tidak akan dibebaskan sampai pada penghakiman terakhir. ${ }^{12}$ Hal lain yang berkaitan dengan sebelumnya adalah, 'Melaksanakan karitas, dengan cara bahwa kamu tidak mengetahui kepada siapa kamu tujukan.'13

Nomor dua dan tiga adalah perintah akan daftar perbuatan yang harus dihindari untuk menuju jalan kehidupan tersebut, seperti tidak membunuh, tidak berzinah, tidak mempraktikkan sihir, tidak mencuri dan lainnya. Salah satu perintah adalah jangan melaksanakan abortus. Untuk melengkapi jalan kehidupan adalah ajakan untuk melaksanakan perintah Tuhan, seperti jangan melaksanakan perselisihan, menjadi perantara perdamaian bagi mereka yang bertengkar, bersikap adil dan lainnya. ${ }^{14}$

Sementara itu jalan menuju kematian diberikan agar orang menghindarinya demi pencapaian jalan kehidupan. Larangan ini kemudian

6 Bdk. Im. 19:18; Deut. 6:5; Eccl. 7:30; Mat. 22:37-39.

7 Bdk. Tob. 4:15; Mat. 7:12; Luk. 6:31.

8 Bdk. Mat. 5:44-47; Luk. 6:27-28, 32, 35.

9 Bdk. Mat. 5:39; Luk. 6:29.

10 Bdk. Mat. 5:40-41; Luk. 6:29.

11 Bdk. Mat. 5:42; Luk. 6:30.

12 Bdk. Mat. 5:26.

13 Didache, 1.

14 Perintah lainnya dapat dilihat dalam Didache, 4. 
akan diulang-ulang pada ajaran moral berikutnya dengan cara sinonim atau analog. Jalan kematian itu adalah kejahatan dan kutukan, seperti,

Membunuh, berzinah, berserakah, bercabul/sundal, mencuri, menyembah berhala, berjimat, merampok, bersaksi palsu, berpura-pura, bercabang hati, menipu; dengki, congkak, tamak, cabul, cemburu, angkuh, megah, sombong, tinggi hati, penghalang baik, pembenci kebenaran, penggemar kepalsuan; mengesampingkan keadilan, tidak peduli akan kebaikan maupun keadilan, tidak berjaga pada kebaikan melainkan pada kejahatan, menjauhkan ketenangan dan kesabaran, menggemari hal-hal yang sia-sia, mengharapkan balasan, bersikap kejam kepada orang miskin, tidak toleran dengan orang tertindas, tidak memedulikan orang lain, membunuh anak, memusnahkan ciptaan Tuhan, tidak peduli pada orang yang membutuhkan pertolongan, menindas orang yang menderita, membela orang kaya, membela kepalsuan orang miskin dan pendosa dengan berbagai cara. ${ }^{15}$

Sesudah itu bagian ini ditutup dengan pernyataan bahwa jika seseorang bisa memikul kuk Tuhan, maka ia akan memiliki hidup sempurna.

Aspek moral ini adalah dasar etika Kristiani yang kemudian diikuti oleh Basilius dari Cesarea (Basilius Agung) (†379). Ia menulis buku moral dengan judul Regula Moral. Metode pemberian pembelajaran moral ini mirip dengan Didache dalam arti, nilai-nilai moral selalu didasarkan pada Kitab Suci. Bahkan Basilius menekankan lebih kaya aspek Kitab Suci setiap kali ia memberikan suatu ajaran moral yang tampak dalam kutipan berikut,

Mereka yang percaya kepada Tuhan, pertama-tama harus melaksanakan pertobatan, menurut pewartaan Yohanes Pembaptis dan Tuhan Yesus Kristus sendiri: mereka yang tidak melaksanakan pertobatan sekarang, akan menerima hukuman lebih berat dari mereka yang telah dihukum sebelum Injil ditulis. Mat. 4:17, Sejak waktu itulah Yesus memberitakan: "Bertobatlah, sebab Kerajaan Sorga sudah dekat!" Mat. 20-23, Lalu Yesus mulai mengecam kota-kota yang tidak bertobat, sekalipun di situ Ia paling banyak melakukan mujizat-mujizatNya,"Celakalah engkau Khorazim! Celakalah engkau Betsaida! Karena jika di Tirus dan di Sidon terjadi mujizat-mujizat yang telah terjadi di tengahtengah kamu, sudah lama mereka bertobat dan berkabung. Tetapi Aku berkata kepadamu: Pada hari penghakiman, tanggungan Tirus dan Sidon akan lebih ringan dari pada tanggunganmu. Dan engkau Kapernaum, apakah engkau akan dinaikkan sampai ke langit? Tidak, engkau akan diturunkan sampai ke dunia orang mati! Karena jika di Sodom terjadi mujizat-mujizat yang telah terjadi di tengah-tengah kamu, kota itu tentu masih berdiri sampai hari ini."16

15 Didache, 5.

16 Basilius dari Cesarea,Regola Morali, 1. A cura di Umberto Neri, traduzione di Mairia Benedetta Artioli(Roma: Città Nuova, 1996). Buku ini dimasukkan ke dalam Regula para eremit yang merinci lebih mendetail dan spesifik akan kehidupan, Basilius dari Cesarea,Le Regole: Regulae fusius tractatae, Regulae brevius tractatae, Introduzione, traduzione e note a cura di Lisa Cremaschi della Comunità di Bose (Magnano: Edizioni Qiqajon - Comunità di Bose, 1993). 
Pada prinsipnya Basilius menulis Regula Moral ini untuk para eremit (pertapa), walaupun ia menujukannya juga kepada Kristiani pada umumnya. Alasannya adalah bahwa buku ini berisikan sikap Kristiani yang seharusnya tampak di dalam hidup. Di samping itu, hidup Kristiani adalah tidak lebih rendah dari hidup eremit dalam kualitas. Apalagi isi buku adalah penjabaran dari hukum kasih yang semuanya bersumber pada Kitab Suci dan didukung oleh kutipan analog sebagai pengembangan setiap peraturan moral yang disampaikan. Seluruh buku memiliki sekitar 1500 kutipan dari Kitab Suci. Bagi Basilius, peraturan atau perintah bersumber pada perintah kasih yang adalah dasar untuk pembentukan moral setiap orang yang kemudian dijabarkan dalam kebajikan-kebajikan.

Dua buku ini, Didache dan Regula Moral dari Basilius, menempatkan peraturan kasih menjadi ajaran moral Kristiani, yang dijabarkan dalam kebajikan dan etika. Peraturan tersebut adalah munculan dari kutipan Kitab Suci yang pararel. Atau dengan kata lain, ajaran moral tersebut yang oleh Basilius ditempatkan di awal setiap peraturan, adalah inti dari seluruh kutipan. Artinya adalah bahwa Kitab Suci adalah sarana hidup untuk menjadi Kristiani yang benar dan pemenuhan peraturan tersebut berada di jalan kehidupan. Kedua buku ini berhasil menerjemahkan Sabda Allah itu (Kitab Suci) agar ditampilkan dalam sikap di dalam kehidupan. Dalam moral Kristiani purba, hanya dua buku ini memberikan pembelajaran moral dengan cara seperti ini. Kemudian para penulis lainnya tidak memiliki cara seperti itu, melainkan menemukan cara tersendiri dengan latarbelakang yang berbeda, yang sudah banyak dipengaruhi etika filsafat, terlebih-lebih Stoicisme.

Ireneus († 202) menghubungkan dua jalan ini dengan hidup eskatologi. Finalisasi kedua jalan itu digambarkan dengan "pengadilan terakhir" untuk mengalokasikan arahan hidup sesuai dengan masingmasing jalan, kehidupan atau kematian. Orang hidup sesuai dengan perintah atau peraturan kasih akan menuju kehidupan yaitu bersama dengan Tuhan, sementara itu orang yang tidak melakukannya, ditempatkan pada api abadi. ${ }^{17}$ Origenes menganalogkan dua jalan ini dengan terang dan gelap yang lebih menekankan pada sikap manusia. Hidup dalam kasih adalah perbuatan terang, yang adalah perbuatan baik yang diidentikkan dengan perbuatan malaikat; sedangkan hidup tanpa peraturan kasih adalah gelap, yang adalah perbuatan jahat yang diprakarsai oleh iblis. Keduanya selalu memengaruhi sikap manusia, yang

17 Ireneus, Against Heresies, 4,40,2, Ante Nicene Fathers, vol. 1, Alexander Roberts and James Donaldson (eds.) (Michigan - Edinburgh: Grand Rapids - T \& T Clark, 1996). Bdk. Mat. 25:32-41. 
satu (terang) mendorong pada perbuatan baik dan yang lain (gelap) pada perbuatan jahat. ${ }^{18}$

\section{Kasih - Kebebasan - Keadilan}

Perjalanan moral Gereja purba selanjutnya adalah pengembangan dari perintah kasih yang telah dijelaskan sebelumnya. Dua unsur sikap moralis yang merupakan pengembangan dari kasih adalah kebebasan dan keadilan. Para penulis moralis setelah Didache menjadikan ketiga prinsip moral ini untuk dilaksanakan dalam bentuk kebajikan. Tidak semua penulis moral ini menggunakan ketiga pilar ini. Kadang ada penulis hanya menekankan satu aspek atau dua aspek, dan ada juga menekankan ketiganya sekaligus. Akan tetapi, walaupun ketiganya adalah pilar, perintah kasih adalah yang paling tinggi. ${ }^{19}$ Kasih menjadi pengembangan kebajikan,$^{20}$ dan karena itu ia (kasih) menjadi lebih unggul darinya. Untuk menggambarkan keunggulan kasih ini, Yohanes Krisostomus mengatakan bahwa ukurannya adalah tidak pernah berhenti untuk mengasihi, melainkan mengasihi dan mengasihi terus menerus. ${ }^{21}$

Pilar kedua akan prinsip moral dalam Gereja purba adalah kebebasan. Alasannya adalah bahwa walaupun Kristus memberikan perintah kasih dan menjadikannya sebagai perintah utama, dan Ia sendiri telah melaksanakan kasih itu dengan sempurna, tetapi kebebasan tetap diberikan kepada manusia. Walaupun bersifat filosofis (Stiociseme), Clemen dari Alexandria dan kemudian dilanjutkan oleh Origenes memberikan alasan kepada manusia untuk memiliki kebebasan. Dalam diri manusia terdapat gambaran Tuhan yang memberikan kepadanya kemampuan untuk memilih (bebas). ${ }^{22}$ Oleh sebab itu, setiap orang memiliki kesempatan untuk memilih dalam dirinya untuk menentukan jalan yang harus dilalui, kehidupan atau kematian. Kebebasan yang diberikan kepada manusia bisa mengakibatkan dosa, bila ia menyalahgunakannya. Akan tetapi berkat kebebasan itu juga, setiap manusia memampukannya untuk berada pada jalan kehidupan.

18 Origenes, De Principiis, 3,2,4, Ante Nicene Fathers, vol. 4, Alexander Roberts and James Donaldson (eds.) (Michigan - Edinburgh: Grand Rapids - T \& T Clark, 1994).

19 Ambrosius. Epistula, 78,9.

20 Yohanes Krisostomus, 1 Corinthians, 33, 2, Nicene and Post Nicene Fathers, vol. 12, Philip Schaff (ed.) (Michigan - Edinburgh: Grand Rapids - T \& T Clark, 1989).

21 Yohanes Krisostomus,Philippians, 2, Nicene and Post Nicene Fathers, vol. 13, Philip Schaff (ed.) (Michigan - Edinburgh: Grand Rapids - T \& T Clark, 1994).

22 Clemen dari Alexandria, The Stromata, 1,11, Ante Nicene Fathers, vol. 2, Alexander Roberts and James Donaldson (eds.) (Michigan - Edinburgh: Grand Rapids - T \& T Clark, 1994). Origenes, De Principiis, 3,6,1. 
Pilar yang ketiga adalah keadilan yang merupakan suatu ungkapan kasih Tuhan kepada manusia. Walaupun manusia menyalahgunakan kebebasannya yang memungkinkan kepada dosa dan berada pada jalan kematian, akan tetapi Ia tetap memberikan kemungkinan kepada manusia untuk menyadarai kedosaannya karena penyalahgunaan kebebasan tersebut. Tuhan adalah sumber keadilan yang seadil-adilnya sehingga membuka pintu kepada mereka yang dalam kondisi penyalahgunaan ini.

Dari ketiga prinsip ini lahirlah berbagai kebajikan yang menuntun setiap orang pada jalan hidup yang sebenarnya. Dengan prinsip kebajikan ini, Kristiani purba berjalan sesuai dengan perintah Kristus, yaitu kasih. Dalam pembelajaran moral pada periode ini, moralis praktis memberikan pembelajaran etika berdasarkan ketiganya, yang banyak tergantung dari masing-masing persoalan moral yang dihadapi.

Ignasius dari Antiokia († c 117) menekankan hukum kasih yang diungkapkan dengan sempurna dengan kemartiran. Cara mati seperti ini adalah imitatio Christi. Sikap dari orang yang memiliki kasih ini lahir dari iman. ${ }^{23}$ Yustinus († 165) memberikan ungkapan kasih itu berdasarkan latarbelakang Kristiani yang selalu dikritisi, ditentang dan dimusuhi oleh banyak orang. Yustinus mengatakan bahwa Kristiani harus menunjukkan sikap untuk mengasihi musuh-musuh, agar mereka mengenal Tuhan yang sesungguhnya. Kasih kepada musuh adalah kekhasan Kristiani yang membedakannya dengan orang lain. ${ }^{24}$ Yustinus juga menghubungkan hukum kasih dengan keadilan. Perintah lama yang diberikan kepada Musa sudah diperbarui dengan perintah kasih yang berlaku untuk semua orang, karena hukum ini adalah keadilan sesungguhnya dan untuk semua orang. ${ }^{25}$ Alasannya adalah jika orang mengasihi Tuhan, maka semestinya ia juga mengasihi sesama. Ditambahkan lagi, kasih kepada sesama adalah keadilan yang sesungguhnya. ${ }^{26}$ Kemudian Yustinus juga menghubungkan kedua hukum itu dengan kebebasan dengan mengatakan, jika manusia tidak menyalahgunakan kebebasan yang dimilikinya, maka kebaikan tidak akan diubah pada kejahatan. ${ }^{27}$

23 Ignasius dari Antiokia, Ephesian, 1, Ante Nicene Fathers, vol. 1, Alexander Roberts and James Donaldson (eds.) (Michigan - Edinburgh: Grand Rapids - T \& T Clark, 1996); Romans, 4; 6; Philadelphians, 7.

24 Yustinus,1 Apology, 14-16, Ante Nicene Fathers, vol. 1, Alexander Roberts and James Donaldson (eds.) (Michigan - Edinburgh: Grand Rapids - T \& T Clark, 1996).

25 Yustinus,Dialogue with Trypho, 11, Ante Nicene Fathers, vol. 1, Alexander Roberts and James Donaldson (eds.) (Michigan - Edinburgh: Grand Rapids - T \& T Clark, 1996).

26 Yustinus,Dialogue with Trypho, 93.

27 Yustinus, 1 Apology, 43. 
Clemen dari Alexandria († c 215) mengikuti jejak penulis sebelumnya mengenai ajaran moral Kristiani. Dengan pengaruh etika stiocisme mengenai hidup yang harmoni dengan alam, ia melengkapi kasih itu dengan kebajikan Kristiani yang pada dasarnya juga harmonis dengan dunia pada umumnya. Prinsip ini berguna untuk bersikap di dalam kehidupan sehari-hari baik itu terhadap sesama maupun terhadap alam. Pemikiran Clemen ini adalah perkembangan moral Krsitiani dibandingkan dengan periode sebelumnya. Dasar pemikiran moral Clemen adalah satu arahan dengan penulis sebelumnya yang melihat bahwa perintah utama adalah kasih yang merupakan sutu harmoni baik itu terhadap Tuhan, sesama dan alam. Hukum kasih kepada Tuhan adalah suatu kesempurnaan. ${ }^{28}$ Dari kasih kepada Tuhan lahir kasih kepada sesama dan alam dan salah satu ungkapan kasih sesama yang sempurna adalah kemartiran, yang bukan karena orang mengakhiri hidupnya bagi orang lain, melainkan karena ia telah mengungkapkan pekerjaan kasih yang sempurna..$^{29}$ Salah satu ajaran moral Clemen adalah perkawinan yang melawan pemikiran Gnosticisme yang menganggapnya sebagai sarana melahirkan iblis. Clemen mengatakan bahwa perkawinan adalah ungkapan kasih sehari-hari yang dijiwai oleh kasih kepada Tuhan, ${ }^{30}$ dan hubungan suami istri dalam kasih adalah suatu persatuan spiritual yang mengantisipasi kehidupan surgawi yang akan datang. ${ }^{31}$ Pada periode Clemen, salah satu fenomena kuat adalah cinta akan uang yang adalah suatu perangkap untuk menyangkal perintah kasih. ${ }^{32}$

Tuhan adalah asal kasih, kata Tertulianus ( $\dagger$ c. 220) yang berada di dalam diri manusia. Mestinya manusia selalu memiliki kasih tersebut. Akan tetapi, dalam kenyataan, manusia bisa berbuat kejahatan. Kasih itu berada di dalam tubuh yang adalah materi yang memungkinkannya untuk berbuat baik dan jahat. Setelah didukung oleh kebebasan yang bersamaan dengan kasih tersebut, manusia dihadapkan untuk membuat pilihan, dan bahkan menyalahgunakannya untuk kejahatan..$^{33}$ Tertulianus telah membuat suatu prinsip moral dengan berkata bahwa kehendak dan keadilan tidak terpisahkan dan berada dalam kesatuan dengan

28 Clemen dari Alexandria,Who is the Rich Man That Shall be Saved?, 27,Ante Nicene Fathers, vol. 2, Alexander Roberts and James Donaldson (eds.) (Michigan - Edinburgh: Grand Rapids - T \& T Clark, 1994).

29 Clemen dari Alexandria, The Stromata, 4,4.

30 Clemen dari Alexandria,The Stromata, 7,12.

31 Clemen dari Alexandria,The Stromata, 6,12; 7,12.

32 Erick Osborn, "Etica", Dizionario Patristico e di Antichità Cristiane, diretto da Angelo Di Berardino, (Institutum Patristicum Augustinianum) (Genova:Marietti, 1994), 1236-1247.

33 Tertulianus, On Repentance, 3, Ante Nicene Fathers, vol. 3, Alexander Roberts and James Donaldson (eds.) (Michigan - Edinburgh: Grand Rapids - T \& T Clark, 1993). 
Tuhan. Ia melanjutkan bahwa kejahatan bukan berasal dari Tuhan. Sementara itu kebaikan adalah rasio dan tergantung dari Tuhan dan berkaitan erat dengan hati nurani yang adalah hukum alam (tertinggi). Hati nurani ini akan memutuskan apa yang hendak dilakukan dan menilai apa yang telah dilakukan. ${ }^{34}$ Bagi Tertulianus, hakekat (natura) adalah hukum untuk semua ciptaan, dan juga termasuk manusia. Kesepuluh perintah Allah yang diberikan kepada Musa di gunung Sinai adalah ungkapan dari hakekat tersebut yang mendapat pemenuhan di dalam hukum yang diberikan Kristus (kasih). ${ }^{35}$ Oleh sebab itu, hakekat Kitab Suci dan kasih adalah suluh untuk moral, tetapi kasih adalah hukum utama dan harta karun Kristiani. ${ }^{36}$

Sehubungan dengan keadilan, Hilairus Poitiers († 368) lebih menekankannya suatu kebajikan untuk menghindarkan berbagai kesalahan. Dua kebajikan yang ditekankannya sebagai kunci pencegahan kesalahan adalah usaha untuk mengontrol diri dari kesombongan yang pasti akan menciptakan rasa lebih dari orang lain. ${ }^{37}$

Atanasius († 373) melanjutkan pemikiran Tertulianus dengan penekanan aspek kebebasan yang telah dikatakan oleh Clemen dari Alexandria dan Origenes. Atanasius mengatakan kebebasan ini dalam bukunya mengenai Inkarnasi Sabda. Penjelmaan Sabda adalah suatu ungkapan kasih Tuhan kepada dunia. Melalui inkarnasi tersebut, gambaran Tuhan dalam kasih hadir di dunia terlebih-lebih di dalam diri manusia. Bersamaan dengan gambaran tersebut, kebebasan juga diberikan kepada manusia untuk menentukan pilihan dalam dirinya, ${ }^{38}$ dan untuk tetap berada pada gambaran Allah tersebut atau ke luar darinya dengan pilihan kejahatan.

Salah satu kejahatan yang menghilangkan gambaran Tuhan yang telah diberikan kepada manusia adalah dosa. Gregorius Nazianzus $(\dagger$ 389) mengatakan bahwa di dunia ini, berkat kasih yang diberikan Tuhan kepada masing-masing manusia, seharusnya berjuang untuk berbuat baik, bukan berjuang untuk kejahatan. Berkat kebebasan yang dimiliki oleh setiap orang dan berkat penyalahgunaannya, perbuatan baik dan jahat

34 Tertulianus, Penance, 12; Apology, 9-11.

35 Tertulianus, Against Marcion, 4,15.

36 Tertulianus, De Fuga in Persecutione, 14; bdk.Scorpiace, 4, kasih menjadi model hidup Kristiani yang saling mengasihi satu dengan lainnya.

37 Hilairus Poitiers,Homily on the Psalm, 14. Bdk. Frederick Norris, "Ethics", Encyclopedia of Early Christianity, Second Edition, Michael P. McHugh, Frederick W. Norris (eds) (New York \& London: Garland Publishing, 1998), hlm. 388-391.

38 Bdk. Atanasius, On the Incarnation of the Word, 4,4, Nicene and Post Nicene Fathers, vol. 4, Philip Schaff and Henry Wace (eds.) (Michigan - Edinburgh: Grand Rapids - T \& T Clark, 1991). 
seakan berjuang untuk saling mengalahkan satu dengan lainnya untuk mencapai kemenangan. Keduanya seakan saling mencekik. Padahal pada dasarnya adalah bukan demikian, karena kejahatan adalah hanya penyalahgunaan kebebasan yang dimiliki masing-masing. Kesadaran akan penyalahgunaan kebebasan tersebut (kejahatan), selalu membuka kembali ke pada kebebasan yang sesuai dengan asalnya, yaitu kasih. ${ }^{39}$

Penulis Gereja purba lainnya yang menekankan kasih, kebebasan keadilan adalah Yohanes Krisostomus († 407) yang menjadikannya sebagai dasar pembelajaran moral. Bagi dia, dosa datang dari kehendak bebas. Setiap orang diberi pengetahuan untuk memilih kejahatan atau kebaikan. Dalam kehendak bebas untuk memilih tersebut, Tuhan selalu hadir, dalam arti Ia selalu berada dalam pergulatan moral manusia dan akan mengadili secara benar pilihan manusia tersebut. Hukum Tuhan (kasih) mengarahkan segala sesuatu dalam diri manusia akan kebaikan dan memberikan hukum alami (interior) yang mampu mengarahkan kehendak untuk melaksanakan yang baik dan menghindarkan yang jahat. ${ }^{40}$ Yohanes mengatakan bahwa kebajikan lahir dan berkembang dari kasih. Jika manusia memiliki kebajikan, kasih tidak akan hilang. Untuk menunjukkannya, Yohanes mengatakan bahwa kebajikan tidak akan memandang uang, orang, dan nafsu, tetapi menanggung segalanya dengan senang hati. Orang seperti ini memiliki kasih yang sebenarnya. Jika satu dengan lain saling memiliki, maka terjadi timbal balik. ${ }^{41}$ Kebajikan-kebajikan lain lahir dari kasih dan demikian juga sebaliknya, kasih mengarah pada kebajikan-kebajikan. Sementara itu kejahatan datang karena ketidak harmonisan kebajikan - kasih di dalam diri manusia.

Pemikiran moral pada periode Kristiani purba juga diberikan oleh Ambrosius († 397). Ia menganalogkan nilai-nilai kebajikan dari Cicero dan Stoicisme dengan etika Kristiani ${ }^{42}$ dalam hal keadilan, kebijaksanaan dan bersikap. Ambrosius mengungkapkan ajaran moralnya bukan dengan menulis buku moral, seperti Basilius Agung, tetapi dengan menunjukkan tanggungjawab dan kewajiban Kristiani, baik itu dalam institusi maupun di luarnya. Dari tanggungjawab dan kewajiban yang sesungguhnya akan mengarahkan kebajikan Kristiani pada yang sesungguhnya. Contohnya, kewajiban seorang filsuf ialah jujur dan memilih yang lebih baik dari

39 Gregorius Nazianzus, Oration, 37,13,Nicene and Post Nicene Fathers, (Second Series), vol. 7, Philip Schaff and Henry Wace (eds.) (Michigan - Edinburgh: Grand Rapids - T \& T Clark, 1996).

40 Yohanes Krisostomus, On the Statutes, 12, 9, Nicene and Post Nicene Fathers, (Second Series), vol. 9, Philip Schaff (ed.) (Michigan - Edinburgh: Grand Rapids - T \& T Clark, 1996).

41 Yohanes Krisostomus, Homily on Ephisian, 9,3.

42 Ambrosius,Officiis, 1,7, 24, Introduzione, traduzione e note di Gabriele Banterle (Milano Roma: Biblioteca Ambrosiana - Città Nuova, 1991). 
yang dibutuhkan. Sementara itu Kristiani juga diajak untuk menjadi jujur dan memilih yang lebih baik, yang bertujuan bukan saja untuk kehidupan sekarang, melainkan juga hidup yang akan datang. ${ }^{43}$ Ambrosius malah berpendapat bahwa orang yang mengenal Tuhan, dengan sendirinya menganugerahkan pekerjaan-pekerjaan baik. ${ }^{44}$ Dalam tulisannya ini bisa dikatakan bahwa kewajiban dan tanggungjawab dengan sendirinya mengarahkan pada kebajikan yang adalah pengungkapan dari kasih.

\section{Agustinus Sebagai Moralis}

Konsep moral dalam Agustinus (†430) dipisahkan dari penulis sebelumnya karena ia memberikan pembahasan mengenai moral secara lengkap. Di samping itu ia telah mengikuti perkembangannya dari tulisantulisan sebelumya. Titik tolaknya sama dengan argumen yang telah dikembangkan oleh Bapa Gereja sebelumnya, yaitu kasih, kebebasan dan keadilan. Ketiganya adalah satu kesatuan dan saling melengkapi satu dengan yang lain. Bagi Agustinus, setiap kebajikan didahului, disertai dan akan didampingi oleh kerendahan hati yang merujuk kepada Tuhan. ${ }^{45}$ Titik tolak Agustinus dalam pembahasan ketiga aspek moral ini bertitik tolak dari perintah kasih, seperti para penulis moral sebelumnya. ${ }^{46}$ Kemudian Agustinus menambahkan bahwa, jika kamu memiliki perintah kasih itu, maka apa saja kamu kerjakan, akan menghasilkan damai; siapa saja kamu tegur dengan kasih akan menghasilkan kebenaran. Biarlah kasih itu mengakar di dalam dirimu yang hanya akan menghasilkan kebaikan. ${ }^{47}$ Bisa dikatakan, aktivitas manusia seharusnya didasarkan pada kasih, kalau ingin menghasilkan kedamaian. Dia hendaknya menjadi energi dari sikap manusia. Manusia juga diajak untuk mencintai ciptaan Tuhan di dunia ini, karena Ia membuatnya dengan kasih, tetapi bukan menyalahgunakan ciptaan itu. Atas dasar ini ia melandaskan hubungan suami-istri yang saling mencintai. ${ }^{48}$ Dasar kasih berasal dari Tuhan yang merupakan hubungan Tritunggal: Bapa, Putera dan Roh Kudus. Tuhan menciptakan manusia dengan kasih, yang menyertakan kasih Tritunggal itu di dalam diri manusia. Inilah dasar

43 Ambrosius, De Officiis, 1,9, 27-28,

44 Ambrosius, De Officiis, 2,2,5.

45 Agustinus, Letter, 118,22, Nicene and Post Nicene Fathers, (First Series), vol. 1, Philip Schaff (ed.), (Michigan - Edinburgh: Grand Rapids - T \& T Clark, 1994).

46 Agustinus, Enarrations on the Psalm, 89,4, Nicene and Post Nicene Fathers, (First Series), vol. 8, Philip Schaff (ed.) (Michigan - Edinburgh: Grand Rapids - T \& T Clark, 1996).

47 Agustinus,Homilies on the First Epistle of John, 7, 8, Nicene and Post Nicene Fathers, (First Series), vol. 9, Philip Schaff (ed.) (Michigan - Edinburgh: Grand Rapids - T \& T Clark, 1991).

48 Agustinus, Homilies on the First Epistle of John, 2,11. 
manusia untuk hidup di dalam kasih tersebut. ${ }^{49}$ Pendasaran paling kuat adalah pernyataan dari Kitab Surat Yohanes yang mengatakan bahwa Tuhan adalah kasih yang diaplikasikannya dalam pembahasannya dengan Tritunggal. ${ }^{50}$

Dalam salah satu tulisannya, Agustinus mendefinisikan kebajikan yang mengambil bentuk dari kasih. Atau dengan kata lain, kabajikan adalah transformasi kasih ke dalam bentuk sikap dan perbuatan (kebajikan). Agustinus memberikan empat kebajikan. Kebajikan pertama adalah murah hati yang adalah pemberian kasih itu sendiri kepada siapa dan apa yang dikasihi. Kebajikan kedua adalah tabah, yaitu sikap kesiapsediaan menanggung segala sesuatu untuk mencapai yang dicintai. Kebajikan ketiga adalah bijaksana, yaitu membedakan antara baik dan jahat. Kebajikan terakhir adalah keadilan yang melayani kebenaran. ${ }^{51}$ Kebajikan ini menjadi suatu penilaian dalam bersikap satu dengan lainnya yang menentukan seseorang itu berjalan benar atau salah. Oleh sebab itu kebajikan menjadi sarana untuk menuju kasih yang sesungguhnya atau memenuhi panggilan Tuhan. ${ }^{52}$ Kasih bersama dengan kebajikan menjadi suatu prinsip penilaian moral. Sehubungan dengan itu, kita bisa mengerti tulisan Agustinus yang berjudul Moral Manikeisme yang berisi penilaian sikap Manikeisme yang hanya berpura-pura, yang sebenarnya bukan sikap seorang Kristiani yang sesungguhnya. ${ }^{53}$

Keadilan mendapatkan penekanan pada Agustinus dibandingkan dengan tiga kebajikan lainnya. Alasannya adalah karena keadilan merupakan suatu manifestasi dari keadilan ilahi yang seharusnya ditampakkan di dunia ini, terlebih-lebih dalam pemerintahan dan sikap kepada sesama. ${ }^{54}$ Akan tetapi di lain pihak dalam pembahasannya dengan kebajikan, keadilan disejajarkan dengan murah hati, tabah dan

49 Agustinus,Morals of the Catholic Church, 10,16-17; 12,20-21; 14,24,Nicene and Post Nicene Fathers, (First Series), vol. 4, Philip Schaff (ed.) (Michigan - Edinburgh: Grand Rapids - T \& T Clark, 1996).

502 Yoh. 4:8. Agustinus.De Trinitate, 8,7,11-12, Introduzione di A. Trapè - M.F. Sciacca, Traduzione di Giuseppe Beschin, Nuova Biblioteca Agostiniana a cura della Cattedra Agostiniana presso l'Augustiniamum di Roma, Direttore di Agostino Trapè, vol. 4 (Roma: Città Nuova, 1987).

51 Agustinus,Morals of the Catholic Church, 15,25.

52 Agustinus, Enarrations on the Psalm, 38,8.

53 Agustinus,Morals of the Manichaeans, Nicene and Post Nicene Fathers, (First Series), vol. 4, Philip Schaff (ed.) (Michigan - Edinburgh: Grand Rapids - T \& T Clark, 1996). Pemikiran Manikeisme bisa dilihat pada tulisan C. Riggi, "Mani - Manicheisme",Dizionario Patristico e di Antichità Cristiane, Diretto da Angelo Di Berardino,Institutum Patristicum Augustinianum (Genova:Marietti, 1994), 2076-2079.

54 Agustinus,City of God, 1,21, Nicene and Post Nicene Fathers, (First Series), vol. 2, Philip Schaff (ed.) (Michigan - Edinburgh: Grand Rapids - T \& T Clark, 1993). 
bijaksana yang merupakan ungkapan dari kasih, yang dirumuskan dengan obyek kasih. ${ }^{55}$

Sebagaimana telah disinggung oleh para penulis moral sebelumnya, kehendak dan kebebasan yang dimiliki manusia adalah juga menjadi pusat pembahasan. Agustinus membedakan dua jenis kebebasan di dalam tulisannya, yaitu kebebasan politik dan religius, walaupun ia lebih menekankan yang kedua, karena berkaitan dengan moral Kristiani. ${ }^{56}$ Alasannya adalah bahwa Berkat kebebasan ini, manusia kadang tidak mampu untuk mengalahkan berbagai cobaan, sehingga jatuh ke dalam kelemahan manusiawi dan dosa. Manusia memiliki kebebasan yang diperoleh dari Tuhan sebagai anugerah. ${ }^{57}$ Melalui kebebasan itu manusia tidak dipaksa untuk memilih kasih atau kejahatan. ${ }^{58}$ Sebenarnya melalui rahmat yang dianugerahkan, manusia selalu dimampukan untuk memilih kasih untuk menjalin hubungannya dengan penciptanya..$^{59}$ Akan tetapi manusia selalu diberi kebebasan dalam dirinya untuk menentukan pilihan di dalam dirinya, yang membuat manusia sering jatuh ke dalam dosa karena penyalahgunaan kebebasan tersebut. Pembahasan pemikiran moral Kristiani purba banyak diberikan oleh Agustinus, karena ia mengembangkannya setelah pembahasan para penulis sebelumnya. ${ }^{60}$ Ia juga telah memberikan penilaian moral pada kehidupan Kristiani, seperti perkawinan misalnya.

\section{Ayub Sebagai Moralis}

Konsep moral di dalam tulisan Gregorius Magnus(†604) memiliki titik tolak yang berbeda dibandingkan dengan penulis sebelumnya. Ambrosius sebenarnya juga telah berbeda dari penulis lainnya, karena ia berangkat dari kewajiban dan tanggungjawab Kristiani untuk menunjukkan kebajikan yang sesungguhnya. Gregorius, bertitik tolak dari tokoh Perjanjian Lama, Ayub. Dengan penafsiran allegoria Kitab Ayub, ${ }^{61}$ ia mampu menarik nilai-nilai moral yang dibutuhkan oleh Kristiani untuk bersikap.

55 Agustinus, City of God, 11,17; 15,22; De Trinitate, 9,14. Lihat juga pembahasan "Justice", Robert Dodaro, "Justice", Augustine Through the Ages: En Encyclopedia, Allan D. Fitzgerald (ed.) (Michigan - Cambridge (UK): William B. Eerdmans Publishing Company - Grand Rapids, 1999),481-483.

56 Marianne Djuth, "Liberty", Augustine Through the Ages: En Encyclopedia, 495-498.

57 Agustinus, Contra Faustum, 8,2, Nicene and Post Nicene Fathers, (First Series), vol. 4, Philip Schaff (ed.) (Michigan - Edinburgh: Grand Rapids - T \& T Clark, 1996).

58 Agustinus, Contra Faustum, 19,13; City of God, 5,10.

59 Agustinus, Letter, 167, 6, 19.

60 Erick Osborn, "Etica”, Dizionario Patristico e di Antichità Cristiane. 1236-1247.

61 Gregorius Agung, Sancti Gregorii Magni: Moralia in Iob, A cura di Paolo Siniscalco, Introduzione di Claude Dagens, Traduzione di Emilio Gandolfo vol. 1-4 (Roma: Città Nuova, 1992). 
Judul buku yang diberikan akan tafsiran tersebut adalah Moralia in Iob yang ditulis sejak tahun 579, sebelum ia terpilih menjadi uskup Roma dan diselesaikan beberapa tahun (600) sebelum ia meninggal. Buku ini memiliki dua tujuan, spiritual dan moral yang keduanya bisa dicapai dengan sangat umum sekali dengan metode penafsiran allegoria yang biasa digunakan oleh para Bapa Gereja, termasuk Gregorius. Keduanya disampaikan secara silih berganti di dalam tafsirannya.

Untuk mencapai nilai moral dan spiritual yang ingin disampaikan, Gregorius menggambarkan Ayub sebagai figur (tipos) dari Yesus Kristus di dalam penderitaan. ${ }^{62}$ Ayub yang sebelumnya adalah seorang pagan, ${ }^{63}$ menjadi orang beriman dan menjadi figur Kristus. Sikap dan iman Ayub ini dijadikan oleh Gregorius sebagai pola hidup Kristiani. Terlebih-lebih mengenai ajaran moral, sikap dan tindakan Ayub adalah cara orang beriman yang dijiwai oleh keilahian. Sikap seperti ini terintegrasi dengan hidup spiritual yang sebenarnya satu kesatuan dengan kehidupan moral. ${ }^{64}$ Berdasarkan figur Ayub ini, Gregorius menarik ajaran moral yang hendak disampaikan, yang kemudian juga diperkaya oleh tulisannya yang lain.

\section{Simpulan}

Moral Kristiani berawal dari perintah Tuhan mengenai kasih yang dijabarkan di dalam sikap yang melahirkan kebajikan. Dalam perkembangan selanjutnya, tiga pilar (kasih, kebebasan dan keadilan) menjadi pengembangan untuk melahirkan kebajikan-kebajikan yang dilaksanakan oleh manusia. Mengapa orang harus bermoral? Para Bapa Gereja berprinsip bahwa dengan pelaksanaan kasih yang diungkapkan dalam kebajikan, akan memenuhi cara hidup Kristiani yang sesungguhnya dan akhirnya sampai ke tujuan hidup.

Para Bapa Gereja telah berusaha membuka jalan untuk cara hidup Kristiani yang sesuai dengan Kitab Suci yang diungkapkan dengan berbagai cara, melalui tokoh Kitab Suci (seperti prinsip moral Gregorius), melalui kewajiban dan tanggungjawab (dikembangkan oleh Ambrosius), melalui sikap seorang eremit (dikembangkan oleh Basilius Agung) dan dengan tiga pilar prinsip moral (kasih, kebebasan dan keadilan). Usaha ini kemudian dikembangan dalam perjalanan moral di dalam Gereja.

62 Tafsiran bisa dilihat, Gregorius Agung,Moralia in Iob, vol 1-4.

63 Gregorius Agung,Moralia in Iob, Praef., 2,5.

64 Gregorius Agung,Moralia in Iob, 32,20,36-39. 


\section{Bibliografi}

\section{Sumber Utama}

Agustinus. De Trinitate.Introduzione di A. Trapè - M.F. Sciacca, Traduzione di Giuseppe Beschin, Nuova Biblioteca Agostiniana a cura della Cattedra Agostiniana presso l'Augustiniamum di Roma, Direttore di Agostino Trapè vol. IV. Roma: Città Nuova, 1987. . City of God. Nicene and Post Nicene Fathers, (First Series) vol. 2, Philip Schaff (ed.). Michigan - Edinburgh: Grand Rapids - T \& T Clark, 1993.

. Contra Faustum. Nicene and Post Nicene Fathers, (First Series) vol. 4, Philip Schaff (ed.). Michigan - Edinburgh: Grand Rapids - T \& T Clark, 1996.

. Letter.Nicene and Post Nicene Fathers, (First Series) vol. 1, Philip Schaff (Ed.). Michigan - Edinburgh: Grand Rapids - T \& T Clark, 1994. . Enarrations on the Psalm.Nicene and Post Nicene Fathers, (First Series) vol. 8, Philip Schaff (ed.). Michigan - Edinburgh: Grand Rapids - T \& T Clark, 1996.

. Homilies on the First Epistle of John.Nicene and Post Nicene Fathers, (First Series) vol. 9, Philip Schaff (ed.). Michigan - Edinburgh: Grand Rapids - T \& T Clark, 1991. . Morals of the Catholic Church.Nicene and Post Nicene Fathers, (First Series) vol. 4, Philip Schaff (ed.). Michigan - Edinburgh: Grand Rapids - T \& T Clark, 1996.

. Morals of the Manichaeans. Nicene and Post Nicene Fathers, (First Series) vol. 4, Philip Schaff (ed.). Michigan - Edinburgh: Grand Rapids - T \& T Clark, 1996.

Ambrosius. Officiis. Introduzione, traduzione e note di Gabriele Banterle. Milano - Roma: Biblioteca Ambrosiana - Città Nuova, 1991.

Atanasius. On the Incarnation of the Word. Nicene and Post Nicene Fathers, vol. 4, Philip Schaff and Henry Wace (eds.). Michigan Edinburgh: Grand Rapids - T \& T Clark, 1991.

Basilius dari Cesarea. Regola Morali.A cura di Umberto Neri, traduzione di Mairia Benedetta Artioli. Roma: Città Nuova, 1996.

. Le Regole: Regulae fusius tractatae, Regulae brevius tractatae. Introduzione, traduzione e note a cura di Lisa Cremaschi della Comunità di Bose. Magnano: Edizioni Qiqajon - Comunità di Bose, 1993.

Clemen dari Alexandria. The Stromata.Ante Nicene Fathers vol. 2, Alexander Roberts and James Donaldson (eds.). Michigan Edinburgh: Grand Rapids - T \& T Clark, 1994. 
Gregorius Agung. Moralia in Iob.(vol 1-4). A cura di Paolo Siniscalco, Introduzione di Claude Dagens, Traduzione di Emilia Gandolfo. Roma: Città Nuova, 1992.

Gregorius Nazianzus. Oration.Nicene and Post Nicene Fathers, (Second Series) vol. 7, Philip Schaff and Henry Wace (eds.). Michigan Edinburgh: Grand Rapids - T \& T Clark, 1996.

Ignasius dari Antiokia. Ephesian. Ante Nicene Fathers, vol. 1, Alexander Roberts and James Donaldson (eds.). Michigan - Edinburgh: Grand Rapids - T \& T Clark, 1996.

Ireneus. Against Heresies. Ante Nicene Fathers vol. 1, Alexander Roberts and James Donaldson (eds.). Michigan - Edinburgh: Grand Rapids T \& T Clark, 1996.

Origenes. De Principiis. Ante Nicene Fathers vol. 4, Alexander Roberts and James Donaldson (eds.). Michigan - Edinburgh: Grand Rapids - T \& T Clark, 1994.

Quacquarelli, Antonio, (Ed.). "Introduzione", I Padri Apostolici. Roma: Città Nuova Editrice, 1994.

Tertulianus. On Repentance. Ante Nicene Fathers vol. 3, Alexander Roberts and James Donaldson (eds.). Michigan - Edinburgh: Grand Rapids - T \& T Clark, 1993.

Yohanes Krisostomus. 1 Corinthians. Nicene and Post Nicene Fathers vol. 12, Philip Schaff (ed.). Michigan - Edinburgh: Grand Rapids - T \& T Clark, 1989.

. On the Statutes.Nicene and Post Nicene Fathers, (Second Series) vol. 9, Philip Schaff (ed.). Michigan - Edinburgh: Grand Rapids - T \& T Clark, 1996.

Yustinus. 1 Apology. Ante Nicene Fathers vol. 1, Alexander Roberts and James Donaldson (eds.). Michigan - Edinburgh: Grand Rapids - T \& T Clark, 1996.

\section{Sumber Penunjang}

Djuth, Marianne. "Liberty".Augustine Through the Ages: En Encyclopedia.Allan D. Fitzgerald (ed.). Michigan - Cambridge (UK): William B. Eerdmans Publishing Company - Grand Rapids, 1999, 495-498.

Dodaro, Robert. "Justice".Augustine Through the Ages: En Encyclopedia.Allan D. Fitzgerald (ed.). Michigan - Cambridge (UK): William B. Eerdmans Publishing Company - Grand Rapids, 1999, 481-483.

Osborn, Erick. "Etica".Dizionario Patristico e di Antichità Cristiane. Diretto da Angelo Di Berardino,Institutum Patristicum Augustinianum. 
Genova: Marietti, 1994, 1236-1247.

Norris, Frederick. "Ethics". Encyclopedia of Early Christianity. Second Edition, Michael P. McHugh, Frederick W. Norris. New York \& London: Garland Publishing, 1998.

Riggi, C. "Mani - Manicheisme". Dizionario Patristico e di Antichità Cristiane, diretto da Angelo Di Berardino, Institutum Patristicum Augustinianum. Genova: Marietti, 1994, 2076-2079. 